
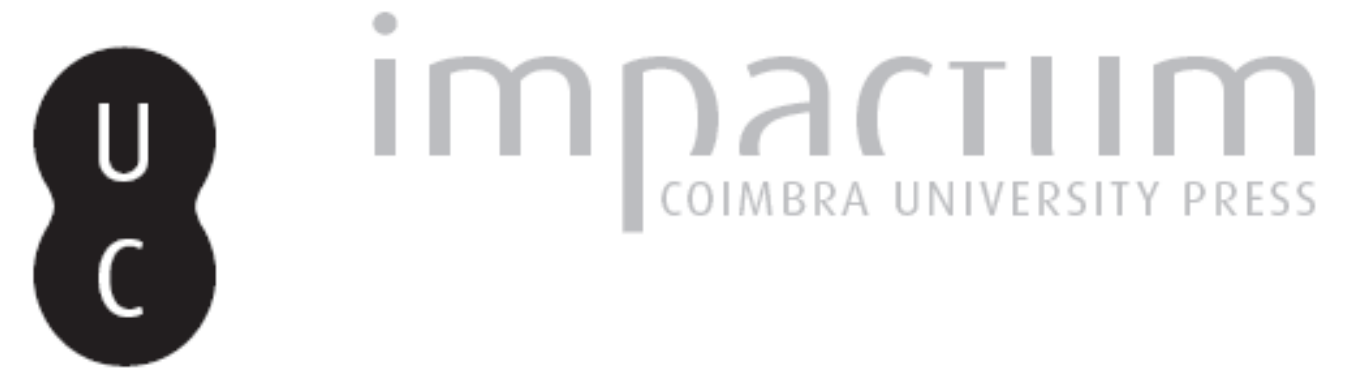

\title{
Ramos Rosa e Pavese: a semântica do silêncio
}

Autor(es): Ragusa, Andrea

Publicado por: Imprensa da Universidade de Coimbra

URL persistente:

URI:http://hdl.handle.net/10316.2/42394

DOI:

DOI:https://doi.org/10.14195/0870-8584_10_8

Accessed : $\quad$ 26-Apr-2023 15:58:25

A navegação consulta e descarregamento dos títulos inseridos nas Bibliotecas Digitais UC Digitalis, UC Pombalina e UC Impactum, pressupõem a aceitação plena e sem reservas dos Termos e Condições de Uso destas Bibliotecas Digitais, disponíveis em https://digitalis.uc.pt/pt-pt/termos.

Conforme exposto nos referidos Termos e Condições de Uso, o descarregamento de títulos de acesso restrito requer uma licença válida de autorização devendo o utilizador aceder ao(s) documento(s) a partir de um endereço de IP da instituição detentora da supramencionada licença.

Ao utilizador é apenas permitido o descarregamento para uso pessoal, pelo que o emprego do(s) título(s) descarregado(s) para outro fim, designadamente comercial, carece de autorização do respetivo autor ou editor da obra.

Na medida em que todas as obras da UC Digitalis se encontram protegidas pelo Código do Direito de Autor e Direitos Conexos e demais legislação aplicável, toda a cópia, parcial ou total, deste documento, nos casos em que é legalmente admitida, deverá conter ou fazer-se acompanhar por este aviso.

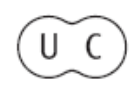




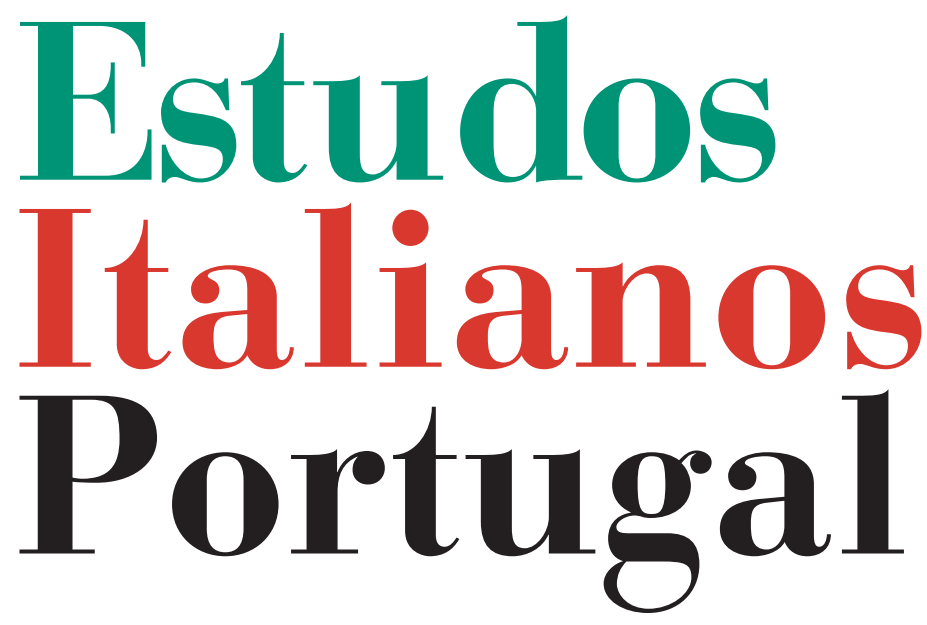

Instituto

Italiano

de Cultura

de Lisboa

Nova Série

$\mathrm{N}^{\mathbf{0}} 10$

2015 


\title{
RAMOS ROSA E PAVESE. A SEMÂNTICA DO SILÊNCIO
}

ANDREa Ragusa*

\begin{abstract}
Na verdade, ao nosso nível de consciência, uma arte esteticamente emancipada não pode deixar de ser o silêncio, uma forma qualquer de silêncio, mesmo daquele silêncio que fala.

Alberto Pimenta, O silêncio dos poetas
\end{abstract}

Nada tem o poeta. Como Orfeu, desce às profundezas da terra e regressa com um canto que ainda não sabe dizer. Procura a "matéria" que permite nomear as coisas, embora nem sempre isso coincida com a possibilidade de as conhecer e com o desejo de estabelecer uma relação total com elas. A poesia representa-se assim como mediadora entre o exprimível o inexprimível, e é nesse sentido que utilizamos a expressão "silêncio órfico", sendo aqui um silêncio que se enche da palavra e que se sublima no canto. A reflexão em torno do silêncio, aliás, surge como reflexão metapoética e constitutiva (particularmente no caso de Ramos Rosa) do "engendramento" do poema. Se a retórica clássica admitia uma diferença fundamental entre os verbos tacère e silère, apesar de

* Doutorando na Universidade Nova de Lisboa. Integra o centro de investigação IELT (Instituto de Estudos de Literatura e Tradição), dedicando-se, em particular, à literatura portuguesa do século XIX e aos estudos comparatistas. Colabora com as editoras Urogallo, Vittoria Iguazu (Itália) e Pianola (Portugal) como tradutor e revisor editorial, e com as revistas Página Aberta, Submarino, Quaderni del CE.PA.M., Estudos Italianos em Portugal, Revista de História de Arte, RiCognizioni e Intervalo. Traduziu para italiano obras de Antero de Quental, José de Almada Negreiros, António Ramos Rosa, Olavo Bilac, José Eduardo Agualusa, João Paulo Borges Coelho e José Castello.

${ }^{1}$ Cf. Gustavo Rubim, "O poema ao engendrar-se", Arte de sublinhar, Lisboa, Angelus Novus, 2003, p. 141.

Est.Ital.Port., n.s., 10, 2015: 133-144 
pertencerem à mesma esfera semântica ${ }^{2}$, já Rebora, Onofri e, sobretudo, Campana, identificam a voz com o silêncio ("le molte voci del silenzio", lemos no poema La notte ${ }^{3}$ ), enquanto as próprias vozes se organizam num "sistema" ${ }^{4}$ que, particularmente em Campana, é abertura, explosão, eco. Pelo contrário, Mallarmé, procurando uma nudez total e livre de qualquer conhecimento, chega a ser quase um anti-Orfeu, enquanto protagonista de uma viagem que se estende de um silêncio interior para um silêncio total, cósmico, eterno, pois a sua direcção não é a de quem procura o Nada para depois regressar ao mundo, mas um silêncio que continua noutro silêncio, feito de harmonia perfeita e luz ${ }^{5}$.

Através da leitura paralela da obra de Cesare Pavese e António Ramos Rosa - escritores que, de facto, nunca estiveram em contacto directo - pode-se evidenciar um fio comum feito de afirmação e negação, renascença (ou resistência) e renúncia, claridade solar e claridade lunar, palavra (ou sílaba) e silêncio. Eduardo Prado Coelho observou que a poesia de Ramos Rosa gravita entre dois pontos: a procura da "matéria” e a interrogação sobre a capacidade de a linguagem dizer o real. Isto dá origem a um drama - cujas personagens são sujeito, objecto e mediador (e a distância entre elas) ${ }^{6}$ - que se desenvolve num processo que chamaremos de "edificação" e, ao mesmo tempo, de "desconstrução". Associando silêncio e

2 Cf. Bice Mortara Garavelli, "Le «tacite congetture» dell'alludere", La retorica del silenzio. Atti del Convegno internazionale (24-27 ottobre 1991), a cura di Carlo A. Augieri, Lecce, Milella, pp. 383-393. Ver também: Luigi Heilmann "Silere / tacere. Nota lessicale", Quaderni dell'Istituto di Glottologia dell'Università di Bologna, 1955-1956, pp. 5-16.

${ }^{3}$ Dino Campana, Canti Orfici, a cura di Fiorenza Ceragioli, Firenze, Vallecchi, 1985 , p. 46.

${ }^{4}$ Cf. Donato Valli, "Silenzio orfico e parola poetica (Semantica del silenzio)", La retorica del silenzio, pp. 363-371.

${ }^{5}$ Cf. Guy Michaud, Message poétique du Simbolisme, Paris, Nizet, 1969, p. 19.

${ }^{6}$ Eduardo Prado Coelho, "Ramos Rosa: onze lâmpadas para iluminar a sua poesia”, A letra litoral, Lisboa, Moraes Editores, 1979, pp. 202-216. 
grito numa identidade, o poeta algarvio inventa a "mediadora" que revela o absconditus da expressão. O silêncio torna-se então num catalisador de significado, um "corpo calado" que se abre no poema':

O grito que não chama, a chama verde

submersa ou não, é a não leitura

do corpo calado que o poema lê. ${ }^{8}$

Já nos Sonetos a Orfeu de Rilke encontramos, logo no primeiro poema, "animais de silêncio" surgindo no sossego de um novo início. E é sobretudo na senda do poeta austríaco que é preciso colocar a parábola órfica novecentista do silêncio, nomeadamente no que diz respeito à obra de Ramos Rosa e Pavese, pois a mesma Vergänglichkeit, a caducidade, está na origem de um novo início, princípio da palavra que brota pelo silêncio:

E tudo emudeceu. E o silêncio inaugura novo começo, sinal, transformação.

Animais de silêncio saíam do arvoredo aberto e claro, dos ninhos de descanso.?

A análise de alguns textos evidencia que os paralelismos entre Pavese e Ramos Rosa se desenvolvem quase sempre em termos de antítese, como variações sobre um mesmo tema. $\mathrm{E}$ isto vale particularmente na semântica do silêncio, elemento essencial e parte integrante do "programa da poesia moderna"10, que contudo, neste caso, não se manifesta quebrando

7 "E o silêncio, o silêncio do grito / é sempre outro [...]". Cf. António Ramos Rosa, O incêndio dos aspectos, Lisboa, Na Regra do Jogo, 1980, p. 15.

${ }^{8} \mathrm{Ib}$.

${ }^{9}$ Vasco Graça Moura, Os sonetos a Orfeu, Lisboa, Quetzal, 1994, p. 9.

${ }^{10}$ Alberto Pimenta, O silêncio dos poetas, Lisboa, Cotovia, 2003, p. 165. 
o compromisso com a palavra e os "símbolos totalitários"11, mas, ao contrário, fixa uma ligação indissolúvel com o símbolo e o mito.

Em Lavorare stanca o silêncio surge como cenário constante, fornecendo coesão ao discurso poético ${ }^{12}$. No primeiro poema, I Mari del Sud, torna-se, de facto, uma "personagem" presente entre o sujeito e a figura mítica do primo, ambos herdeiros da comum "virtude" de calar:

Camminiamo una sera sul fianco di un colle, in silenzio. Nell'ombra del tardo crepuscolo mio cugino è un gigante vestito di bianco, che si muove pacato, abbronzato nel volto, taciturno. Tacere è la nostra virtù.

Qualche nostro antenato dev'essere stato ben solo - un grand'uomo tra idioti o un povero folle per insegnare ai suoi tanto silenzio. ${ }^{13}$

$\mathrm{O}$ poema de abertura não introduz apenas o motivo frequente do regresso, mas também valoriza a faceta "ancestral" da palavra, onde por "palavra” se entende um fenómeno quase raro, uma explosão que surpreende:

Mio cugino ha parlato stasera. Mi ha chiesto se salivo con lui $[\ldots] .{ }^{14}$

${ }^{11} \mathrm{Ib}$., pp. $167-168$.

${ }^{12}$ Marziano Guglielminetti, "Racconto e canto nella metrica di Pavese", Sigma. Rivista Trimestrale di letteratura, 3-4, 1974 [Torino, Libreria Stampatori], pp. 22-33.

${ }^{13}$ Cesare Pavese, Le poesie, a cura di Mariarosa Masoero, introduzione di Marziano Guglielminetti, Torino, Einaudi, 1998, p. 7. A propósito do tema do silêncio na obra de Cesare Pavese, ver também: Giuseppe Zaccaria, "Dal mito del silenzio al silenzio del mito: sondaggi pavesiani”, La retorica del silenzio, pp. 346-362.

${ }^{14}$ Cesare Pavese, Le poesie, p. 7. 
O "gigante vestido de branco", contudo, não fala italiano, mas utiliza "pausado" o dialecto, que substitui um código íntimo de comunicação:

Tutto questo mi ha detto e non parla italiano,

ma adopera lento il dialetto, che, come le pietre

di questo stesso colle, è scabro tanto

che vent'anni di idiomi e di oceani diversi

non gliel'hanno scalfito. ${ }^{15}$

Esta atmosfera de silenciosa cumplicidade mantém-se ao longo do conjunto poético. Em Crepuscolo di sabbiatori, por exemplo, o silêncio é "ocupado" pela imagem do crepúsculo "reconstruído": "Ora tornano tutti i sussulti, intravisti nell'erba, / a occupare il silenzio e ogni cosa s'accentra / sulla punta di fuoco, che vive"16. Em Ritratto d'autore funciona como epílogo que delimita o quadro e fecha a acção: "Quando è qui, stendo un piede. Va subito in terra / e gli chiedo una cicca. Fumiamo in silenzio" ${ }^{17}$. No poema Fumatori di carta, que evoca a figura de Pinolo Scaglione - o futuro Nuto de La luna e i falò - tocando o clarim na banda que ele próprio "instruiu", o silêncio contrapõe-se literal e constantemente à música do conjunto, como num contracanto:

E il clarino si torce,

rompe il chiasso sonoro, s'inoltra, si sfoga

come un'anima sola, in un secco silenzio. ${ }^{18}$

Só o "grito", enfim, repentino ("d'un tratto gridò") e quase inesperado, parece possuir a força para quebrar o silêncio que

\footnotetext{
${ }^{15} \mathrm{Ib}$.

${ }^{16} \mathrm{Ib}$., p. 88.

${ }^{17} \mathrm{Ib} .$, p. 49.

${ }^{18} \mathrm{Ib}$., p. 96.
} 
persiste $^{19}$. Em La terra e la morte é a própria figura da mulher (lembramos também que o conjunto é dedicado a Bianca Garufi) que está envolvida num "doce silêncio"20, gerando uma sobreposição com a terra, mas uma "terra má", que tem, sim, "doçuras" e "fértil" sensualidade, mas também mistério:

C'è una terra che tace

e non è terra tua.

C'è un silenzio che dura

sulle piante e sui colli.

$\mathrm{Ci}$ son acque e campagne.

Sei un chiuso silenzio

che non cede, sei labbra

e occhi bui. Sei la vigna.

Terra também que, apesar de silenciosa, necessita de ser dita, contada:

Tu sei come una terra

che nessuno ha mai detto.

Tu non attendi nulla

se non la parola

che sgorgherà dal fondo

come un frutto tra i rami. ${ }^{21}$

A compenetração entre tacere e silere faz-se aqui mais evidente:

Nel cuore

hai silenzio, hai parole

inghiottite. Sei buia.

Per te l'alba è il silenzio..22

\footnotetext{
${ }^{19} \mathrm{Ib}$., p. 97.

20 "Sarà dolce tacere. / Sei la terra e la vigna. / Un acceso silenzio / brucerà la campagna / come i falò la sera.", ib., p. 123.

${ }^{21} I b .$, p. 122.

${ }^{22}$ Ib., p. 124.
} 
No poema La voce, o silêncio, de facto, substitui a própria "voz" principal, como acontecia em Fumatori di carta:

Ma la voce non torna, e il sussurro remoto non increspa il ricordo. L'immobile luce dà il suo palpito fresco. Per sempre il silenzio tace rauco e sommesso nel ricordo d'allora. ${ }^{23}$

Pode-se dizer que na obra do escritor piemontês o silêncio é um contracanto que funciona como estrutura, ao passo que na poesia de António Ramos Rosa se manifesta uma contínua procura do silêncio como fonte de reflexão, ponto de partida ("O silêncio era a nascente"24) e, ao mesmo tempo, fio condutor, "inocência"25, para construir um poema infinito ${ }^{26}$ :

O simples se diz com a assinatura extrema na ardósia do silêncio ${ }^{27}$

No silêncio vive a palavra pobre e "muda", exaltando a nudez em que o poema se enraíza e desenvolve na simplicidade que lhe pertence:

Quem ouviu tal silêncio quem ouviu tal deserto quem dormiu nesta cama só poderá desejar o súbito milagre do mundo muito para além dos olhos sujos dos homens ${ }^{28}$

\footnotetext{
${ }^{23}$ Ib., p. 92.

${ }^{24}$ António Ramos Rosa, Facilidade do ar, Lisboa, Caminho, 1990, p. 11.

25 "E a coluna / vertebral incandescente na inocência do silêncio", $i b$.

${ }^{26}$ Cf. Nuno Júdice, "A construção do poema em António Ramos Rosa”, A viagem das palavras, Lisboa, Ediçōes Colibri-IELT, 2005, pp. 103-108.

${ }^{27}$ António Ramos Rosa, Facilidade do ar, p. 17.

28 Id., Obra poética, Coimbra, Fora do Texto, 1989, p. 44.
} 
A poesia de Ramos Rosa é sempre uma procura do essencial que passa pelo equilíbrio entre voz e silêncio, estritamente dependentes da capacidade de olhar. Como observou Gastão Cruz ${ }^{29}$, no volume Nos seus olhos de silêncio emerge a necessidade de evocar o olhar, ecoando os versos de $O$ grito claro, e antecipando Estou vivo e escrevo sol:

São palavras, palavras. São

palavras.

Não respiram. Não falam.

São desertas ${ }^{30}$

É importante realçar um exemplo em que o poeta português concentra olhar e silêncio na figura de Murilo Mendes. A obra do poeta brasileiro - como observou Joana Matos Frias $^{31}$ - está envolvida num essencialismo que é a fonte do seu próprio equilíbrio e é mesmo no olhar de Murilo Mendes que se encontram as vozes originárias e o silêncio ("O olhar de Murilo Mendes abre-se às forças da origem / e num lento silêncio até o fundo do imóvel" 32 ), misturando-se visão e ouvido, numa "nupcial articulação":

E o olhar abre-se imensamente às nascentes nocturnas captando o eco perdido em cada coisa ${ }^{33}$

Ora, na poesia de António Ramos Rosa o silêncio aparece sobretudo como um espaço fértil à espera de ser habitado,

${ }^{29}$ Gastão Cruz, "Nudez, evidência, pobreza, nas palavras de António Ramos Rosa. A propósito de Nos Seus Olhos de Silêncio", A poesia portuguesa hoje, Lisboa, Relógio d'Água, 1999, pp. 92-95.

${ }^{30}$ António Ramos Rosa, Antologia poética, selecção, prefácio e bibliografia de Ana Paula Coutinho Mendes, Lisboa, Dom Quixote, 2001, p. 147.

${ }^{31}$ Joana Matos Frias, "A poética essencialista de Murilo Mendes", Revista da Faculdade de Letras "Linguas e Literaturas", 17, 2000, pp. 287-305.

${ }^{32}$ António Ramos Rosa, Facilidade do ar, p. 13.

${ }^{33} \mathrm{Ib}$. 
à espera de "acontecer" ("Aconteceram hoje palavras como folhas / na tua nuca de silêncio"34), espaço que funciona também como imagem, impulso inicial de toda a criação. Em Proposiçôes sobre "Le Domaine enchanté" de Magritte, o poeta realça precisamente - como numa arte poética - essa "promessa de sentido":

O que nos diz a imagem? Diz-nos o que é e não o diz.

Porque não é uma palavra. Antes um silêncio.

O seu sentido é uma promessa de sentido. ${ }^{35}$

\section{Semelhante observação lê-se em $A$ parede azul:}

É que, em verdade, o silêncio na poesia é uma comunicação essencial com o desconhecido ou o indizível. ${ }^{36}$

Em A festa do silêncio a "inocência aberta" é alcançada por meio de uma palavra encolhida, guardada num silêncio capaz de "apagar" as aparências:

Escuto na palavra a festa do silêncio.

Tudo está no seu sítio. As aparências apagaram-se.

As coisas vacilam tão próximas de si mesmas.

Concentram-se, dilatam-se as ondas silenciosas.

É o vazio ou o cimo? É um pomar de espuma. ${ }^{37}$

${ }^{34}$ António Ramos Rosa, Antologia poética, p. 86. Acerca da "fertilidade" na poesia de Ramos Rosa ver também Vergílio Ferreira, "Aridez fecunda, claridade", Espaço do invisível. Ensaios, Venda Nova, Bertrand Editora, s. d, vol. 1, pp. 261271.

${ }^{35}$ António Ramos Rosa, Antologia poética, p. 106.

${ }^{36}$ António Ramos Rosa, A parede azul. Estudos sobre poesia e artes plásticas, Lisboa, Caminho, 1991, p. 16.

${ }^{37}$ António Ramos Rosa, Antologia poética, p. 234. 
O oximoro ${ }^{38}$ é superado através de um acto de "concentração" e "dilatação" que é, de facto, mais um acto de criação, pois silêncio e poema tornaram accessível o inacessível:

Nada é inacessível no silêncio ou no poema.

É aqui a abóbada transparente, o vento principia.

No centro do dia há uma fonte de água clara.

Se digo árvore a árvore em mim respira.

Vivo na delícia nua da inocência aberta. ${ }^{39}$

Maria Graciette Besse, abordando o tema do silêncio na poesia de António Ramos Rosa, propunha cinco "linhas de força de toda a obra": a) A palavra; b) A alegria de viver; c) A sede de uma nova dimensão; d) $\mathrm{O}$ retorno à origem, a busca do inicial; e) A fraternidade para com os homens e as coisas; f) A tensão-atenção ao movimento interior do poema ${ }^{40}$. É importante realçar que é mesmo nessa suposta "alegria de viver" que se iriam manifestar as principais antinomias em relação à obra de Cesare Pavese. Se na poesia de Ramos Rosa o sujeito chega a identificar-se com "a tranquilidade dos montes", "a claridade de tudo" 41 e a alegria de possuir a vida, no caso do autor de Lavorare stanca, pelo contrário, a poesia nunca é consolação ou felicidade tangível e dizível, mas, quando muito, surge como "promessa de uma vida ignota”.

Mesmo sem abordar em pormenor a prosa pavesiana, é necessário um breve excursus pela sua narrativa para percebermos com maior clareza essa faceta, considerando que, para

${ }^{38}$ Acerca deste aspecto na poesia de Ramos Rosa ver também Nuno Júdice, "A construção do poema em António Ramos Rosa”, pp. 103-108.

${ }^{39}$ António Ramos Rosa, Antologia poética, p. 234.

${ }^{40}$ Maria Graciette Besse, "A palavra e o silêncio na poesia de António Ramos Rosa”, Colóquio. Letras, 61, Maio de 1981, pp. 30-38. O estudo limitava-se à produção ramosrosiana de 1958 a 1970, portanto de O grito claro a Nos seus olhos de silêncio.

${ }^{41}$ António Ramos Rosa, Estou vivo e escrevo sol, Lisboa, Ulisseia, 1966, p. 24. 
Pavese, a "fuga na metáfora" 42 é uma das principais razōes da escrita. Em Paesi tuoi, por exemplo, a metáfora gerada pelo símbolo transforma as obsessōes (sexo, sangue, morte) em figuras ou momentos filtrados pela etnografia (sacrifício, ritual, santuário). Não é por acaso que neste caso o modelo é Sanctuary de William Faulkner. Mas aqui o silêncio traduzse numa não-expressão que, por sua vez, transmite um valor mítico e um sentido ritual ${ }^{43}$.

No conto Il campo di granturco é oferecido um exemplo teórico-prático da função do silêncio através do diálogo entre um rapaz e um campo de milho. O campo, que no universo pavesiano é o ponto ideal de regresso, aparece como lugar onde o diálogo acontece sem a mediação da palavra:

Nulla mi deve quel campo, perché io possa far altro che tacere e lasciarlo entrare in me stesso. E il campo, e gli steli secchi, a poco a poco mi frusciano e mi si fermano in cuore. Tra noi non occorrono parole. Le parole sono state fatte molti anni fa.

[...]

C'era in quel crepitio un silenzio mortale, di luogo chiuso e deserto, che chiudeva nel cielo lontano una promessa di vita ignota, impervia e seducente come le colline. ${ }^{44}$

Um aspecto importante da obra de Pavese está precisamente na partilha do silêncio. No diálogo L'isola, Calipso evoca "presenças desaparecidas", tentando convencer Ulisses a abandonar a sua ânsia de regressar a casa mesmo através desse "recíproco bem":

${ }^{42}$ Giorgio Bàrberi Squarotti, "Pavese o la fuga nella metafora”, Sigma. Rivista Trimestrale di Letteratura, 3-4, 1974, pp. 165-188.

${ }^{43}$ A este respeito ver também Cesare Pavese, "Del mito, del simbolo e d'altro", $L a$ letteratura americana e altri saggi, Torino, Einaudi, 1968, pp. 271-276.

${ }^{44}$ Cesare Pavese, Feria d'agosto, introduzione di Marco Forti, Milano, Mondadori, 1971, p. 49. 
Ma non senti anche tu certi giorni un silenzio, un arresto, che è come la traccia di un'antica tensione e presenza scomparse?

[...]

È un reciproco bene Odisseo. Non c'è vero silenzio se non condiviso. ${ }^{45}$

Contudo, a procura do silêncio não chega neste caso, come se disse, a uma "recusa integral da mimese e do mito" ${ }^{46}$. $\mathrm{Na}$ obra de Pavese e Ramos Rosa nunca se põe totalmente de lado o compromisso com o "medium da totalidade" 47 , pois a obra pára aquém da fronteira que separa o "silêncio que fala ${ }^{48 "}$ da "abolição da obra" ${ }^{49}$. Essa mesma retórica do silêncio advém da palavra e vai na direcção da palavra: nesse sentido, compreender, manusear e dizer o silêncio são valores absolutos da poesia.

\footnotetext{
${ }^{45}$ Cesare Pavese, Dialoghi con Leucò, Torino, Einaudi, 1947, p. 102.

${ }^{46}$ Alberto Pimenta, O silêncio dos poetas, p. 165.

${ }^{47}$ Ib., p. 170.

${ }^{48} \mathrm{Ib}$., p. 173.

${ }^{49} \mathrm{Ib}$.
} 